\title{
Human Immune Virus positive status disclosure to a sexual partner and associated factors among adult clients in Debre Markos town, 2019
}

Mengistu Benayew Shiferaw ( $\nabla$ mengistubinayew7@gmail.com )

Debre Markos University

Muluken Teshome

Debre Markos University

Haymanot Zeleke

Debre Markos University

Agumas Fentahun Ayalew

Salale University

Research article

Keywords: Human Immune Virus, Disclosure, sexual partner, Debre Markos

Posted Date: January 20th, 2020

DOI: https://doi.org/10.21203/rs.2.21282/v1

License: (c) (i) This work is licensed under a Creative Commons Attribution 4.0 International License.

Read Full License 


\section{Abstract}

\section{Background}

Human Immune Virus' positive status non-disclosure to a sexual partner is a public health problem where a high prevalence of Human Immune Virus infection is reported on a region with poor partner disclosure status. The aim of this study was to assess Human Immune Virus positive status disclosure to sexual partners and associated factors among adult Human Immune Virus positive clients at Debre Markos town, Amhara Regional State Ethiopia, in, 2019.

\section{Methods}

Facility based cross-sectional study was done among 421 adult Human Immune Virus positive clients in Debre Markos town from September 1-30-2019. Consecutive sampling was used to collect the data. Epidata version 3.1 for data entry and SPSS version 25 for data analysis were used. Hosmer-Lemeshow goodness test of model fitness was checked. Bivariable and multivariable logistic analysis $(p<0.05)$ was performed.

Results

The median age of participants was 35 years with (IQ of 30-42). Human Immune Virus positive status disclosure was 73.4\% (95\%, Cl: 69-78). Male Sex (AOR=3.04; 95\%, Cl: 1.75-5.27), urban residence $(A O R=2.57 ; 95 \%, C l: 1.39-4.77)$, Good antiretroviral treatment adherence status (AOR=3.18; 95\%, Cl: 1.586.39), stayed 39 months and above on antiretroviral treatment (AOR=4.53; 95\%, Cl: 2.31-8.88), Knowing sexual partner's Human Immune Virus status (AOR=2.74; 95\%, $\mathrm{Cl}$ : 1.63-4.63) and provider-initiated Human Immune Virus testing (AOR=2.18; 95\%, Cl: 1.21-3.92) were statistically significant associated factors with Human Immune Virus status positive status disclosure.

Conclusions and recommendation

Human Immune Virus' positive status disclosure to sexual partner was low. Sex, Residence, Duration of Anti-Retroviral Treatment, Adherence status to antiretroviral treatment, provider-initiated Human Immune Virus testing and knowing sexual partner`s Human Immune Virus status have had a statistically significant association with disclosure. It is better to promote provider-initiated Human Immune Virus testing and give special attention to females and rural residents regarding Human Immune Virus status disclosure to sexual partners.

\section{Background}

Disclosure of HIV (Human immune virus) positive status is defined as a process of communicating potentially stigmatizing information that had been previously kept hidden in order to increase one's psychological well-being, and in the case of disclosure to sexual partners, to preserve the quality of 
relationships (1). WHO (World Health Organization) recommends all HIV positive patients should immediately disclose their HIV positive status to prospective sexual partners (2).

Knowing once HIV positive status along with disclosure to sexual partner has a significant implication and plays a vital role in the prevention and control of HIV/AIDS as it allows individuals to access HIV care and treatment services, encourages partners to seek testing, change behavior, and to create awareness and practice of safer sex behavior (3),(4).

Disclosure of HIV positive status allows couples to make informed reproductive health choices by reducing undesirable pregnancies and the risk of maternal to child HIV transmission (3).

International organizations including United Nations Program on HIV/ADIS (UNAIDS), WHO and center for disease control (CDC) highlight the significance of HIV positive status disclosure for the public health and place stress on disclosure among HIV-infected clients, particularly to their sexual partners $(5,6)$.

HIV positive status non-disclosure to a sexual partner is a public health problem in the prevention and treatment efforts of HIV infection, where higher HIV transmission risk is reported in a high HIV prevalence region with poor partner disclosure status compared with lower HIV transmission risk in low HIV prevalence region with better disclosure status to sexual partner (7).

Disclosure of HIV positive status to sexual partners offer numerous benefits to the infected person as well as to the larger community; However, despite this potential benefits, incidences, and determinants of the disclosure have not been comprehensively reported, particularly in hyper-endemic settings including Ethiopia (1).

In Ethiopia, a lack of disclosing HIV positive status to sexual partners had shown to limit women's ability to participate in the prevention of mother to child HIV transmission programs (8). Similarly, a higher percentage of poor HAART adherence were reported among HIV positive patients who did not disclose their HIV positive status to a sexual partners (9).

The actual threat faced by the person who disclosed HIV positive status such as stigma, discrimination, rejection, divorce, blame, and shame were known to hinder disclosure and reduce the pace of HIV prevention by creating anxiety to the person being infected $(10,11)$.

The issue of HIV positive status disclosure to sexual partner still needs to be addressed to prevent the spread of HIV infection and promotes accessibility to care and treatment programs, attain psycho-social support from partners, reduce stigma, adhere to treatment and promote safer health behaviors.

Identifying factors associated with disclosure is a research priority as a high proportion of people living with HIV/AIDS never disclose in Ethiopia.

Therefore, conducting further studies in an area where no previous assessment was done helps to improve disclosure status by creating strategies and implement an effective intervention on identifing 
influencing factors. So this study was used to assess the level of HIV positive status disclosure to sexual partners and associated factors among adult Human Immune Virus positive clients at ART clinics in Debre Markos town, Amhara Regional State Ethiopia, in, 2019.

\section{Methods}

\section{Study Area}

Debre Markos is the administrative city of East Gojjam Zone, which is located $300 \mathrm{~km}$ away from Addis Ababa, which is the capital city of Ethiopia and $265 \mathrm{~km}$ from Bahir-Dar is the capital city of Amhara Regional State. This town has 01 referral hospital, 04 governmental health centers, 07 health posts, 16 private pharmacies, 22 private clinics, 02 diagnostic laboratories, and 12 traditional healer service providers. The study was conducted in those four ART clinics found in this town. These ART clinics are currently providing VCT, PMTCT, antiretroviral treatment, opportunistic infection treatment, TB/HIV Coinfection treatment, and care of HIV exposed infants services. According to Debre Markos town, the administration, the total population of this town projected at 483,127 in 2018 . In this town there were 5088 clients who had ART follow-ups and users of ART clinics.

\section{Study Design and Period}

Facility based cross sectional study design was conducted from September 1-30/7/2019.

\section{Population}

\section{Source Population}

All adult HIV positive clients who had ART follow up care at Debre Markos town ART clinics during the study period.

\section{Study Population}

All adult HIV positive clients on ART follow-up care and who had a sexual partner during their HIV diagnosis and were available during the study period at Debre Markos town ART clinics.

\section{Inclusion Criteria}

Age $\geq 18$ years, had a sexual partner during their HIV diagnosis and, being on ART follow up care for at least one-month duration during the data collection period. 


\section{Exclusion Criteria}

The couple tested HIV positive clients were excluded from the study.

\section{Sample Size Determination and Sampling Techniques}

The final required sample size was determined by taking the largest of the two after calculating the sample size for the two objectives separately. For the first objective, sample size was calculated by using a single population proportion formula, which considers the proportion of HIV status disclosure $52.6 \%$ from previous studies conducted in Bale Zone Hospitals, Oromia Region (12) With marginal error of 5\%, $5 \%$ level of significance and $95 \%$ confidence interval.

$n=(Z a / 2)^{2} p(1-p) / d^{2}$

Where $\mathrm{n}=$ sample size

$Z=$ value corresponding to $5 \%$ level of significance $=1.96$

$\mathrm{P}=0.526$ is the proportion of HIV Seropositive status disclosure to a sexual partner.

$q=(1-p)=(1-0.526)=0.474$

$d=$ Margin of error assumed to be $5 \%$. Therefore, $n=(1.96)^{2} \times 0.526 \times 0.474 /(0.05)^{2} n=383$. Therefore, by adding $10 \%$ non-response rates, the required sample size using this objective was $n 1=421$.

For the second objective (for different factors which has an association with HIV status disclosure), the sample size was calculated using Epi 7 software with the assumption of $95 \%$ confidence level, $80 \%$ power and 1:1 exposed to unexposed ratio [Table 1]..

Based on this assumption, the required sample size was $\mathrm{n} 2=370$ and after adding a $10 \%$ non-response rate, it was $n 2=407$.

Therefor the final required sample for this study was the larger of the two which was sampled size calculated by using the first objective equals $n=421$.

There are four ART clinics in Debre Markos town. These are Debre Markos Referral Hospital ART clinic, Debre Markos Health center, ART clinic, Hidase Health center, ART clinic and Wuseta Health center ART clinic. First, the total number of ART clients was identified from each selected ART clinic. Second, the required sample sizes of ART clients were distributed independently among all ART clinics proportionally based on the total number of clients on each ART clinic. Finally, study participants were selected by systematic random sampling technique, considering different $\mathrm{K}$ values for each ART Clinic and using their arrival to the ART clinic as a sampling frame during the period of data collection. Accordingly, 314, 100, 4 and 3 study participants were sampled from Debre Markos Referral Hospital ART clinic, Debre 
Markos Health center, ART clinic, Hidase Health center ART clinic and Wuseta Health center ART clinic respectively.

\section{Study Variables}

\section{Dependent Variable}

HIV positive status disclosure to sexual partner

\section{Independent Variables}

Socio-demographic related factors: Age, sex, marital status, ethnicity, religion, residence, occupation, educational status, living with a sexual partner and having children

Clinically related factors: Health status at the time of HIV diagnosis, baseline WHO clinical stage of the disease, duration on ART follow up care, type of HIV testing

Partner related factors: Number of current and lifetime sexual partners, dominancy relationship, knowing the partner's HIV status, prior discussion about HIV testing, relationship status before HIV diagnosis, use of substances,

Social related factors: Being a member of the anti- HIV/AIDS club, see a public HIV sero-positive status disclosure.

\section{Operational or Standard Definition}

Sexual partner: Is someone's husband/wife if they are married and someone's girlfriend or boyfriend if they are single.

Current sexual partner: Is sexual partner who are study participants had while he/she had testing HIV positive.

Lifetime sexual partner: Is a total number of sexual partners the person had in his/her lifetime.

HIV positive status disclosure to sexual partner: In this study, it is defined as when an HIV positive person told to all his/her sexual partners that he/she is HIV infected(1).

Delayed disclosure: In this study, it is defined as disclosure of HIV positive status to a sexual partner/s after one month of HIV positive diagnosis(13). 
Risky sexual practice before disclosure: defined as when an HIV positive individual had unprotected sex (sex without condom) with a sexual partner before disclosed his/her HIV positive status

\section{Data Collection Tools and Procedure}

Data were collected by pre-tested and structured interviewer-administered questionnaire which was adapted from previous related studies conducted in Ethiopia $(9,12-14)$. The questionnaire was first, prepared in English, then translated into the local language (Amharic) and back to English to assure its consistency. Finally, the Amharic version was used for the data collection.

Five ART trained, diploma nurses from other work units were recruited and trained about tools, data collection procedure and from them; two were assigned in Debre Markos Referral hospital ART clinic, one in each other ART clinic. And four B.Sc. Nurses from other working units were recruited for supervision in these ART clinics and training of data collectors was provided by the principal investigator for two days before the actual data collection

Participants were approached and interviewed while they came to their medical appointments, screened for eligibility, given information about the purpose of the study and requested to participate. Those that agreed to participate after informed consent was obtained were interviewed on exit after they had got their treatment from the health care providers.

\section{Data Quality Assurance}

A pretest was done in 21 (5\%) of a sample size of Dejene health center, ART clinic one week before the actual data collection and any ambiguity, confusion, difficult words and differences in understanding were revised and corrected based on pretest experience. Then training of data collectors and supervisors on objectives, questionnaires, and ways of collecting the data was given for two days before the actual data collection time. Before proceeding with the interviewing, client confidentiality was upheld and private counseling space was offered that was free from interruption. The data collectors were supervised by four supervisors; one in each four selected ART clinics. Before entry, data were checked for completeness and coded.

\section{Data Processing and Analysis}

Data entry was made using Epidata 3.1 Software. The entered data were exported to the SPSS statistical package version 25 for analysis. Before the analysis, data were cleaned for possible errors. Model assumption of logistic regressions and Hosmer and Lemeshow goodness of model fitness were checked. The Bivariable analysis was carried out to identify candidate variables for multivariable analysis. Variables with $\mathrm{p}$-value $<0.25$ in Bivariable analysis were included in multivariable logistic regression. Then multiple logistic regression analysis using forward selection methods was performed and 
investigates independent predictors by controlling for possible confounders. AOR at $95 \% \mathrm{Cl}$ with $\mathrm{p}$-value < 0.05 was estimated to identify the associated factors on multivariable logistic regression. Variables in multiple logistic regression were interpreted as having a statistically significant association with the dependent variable when $p<0.05$.

\section{Ethical Consideration}

First, the ethical clearance letter was obtained from the Ethical Review Committee of the Debre Markos University, College of health science. A permission letter was obtained from each health facility administrative body and given to the respective ART unit. The Data collection was made after written consent was taken from each participant. The privacy and confidentiality of the respondents were ensured by excluding the name on the questionnaire and interviewed them in a private space that is free from interruption and cannot be observed or heard by other people within the facility environment.

\section{Result}

\section{Socio-demographic characteristics}

The totals of 421 adult HIV positive patients were participated, giving a $100 \%$ response rate. The median age of participants was 35 years with (IQ of 30-42) and $43.2 \%(n=182)$ of them were in the age group of 28-37 years. Of the total study participants, $52.5 \%(n=221)$ of them were females. Most of the study participants, $97.6 \%(n=411)$ and $98.6 \%(n=414)$ were orthodox in religion and Amhara by ethnicity. In marital status, $62.7 \%(n=264)$ of study participants were married. About $32.1 \%(n=135)$ of respondents were attended secondary school and above and $80.0 \%(n=337)$ of them were urban residents [Table 2].

\section{Clinical Condition, partner and social of related factors}

Regards to HIV testing type, $60.8 \%(n=256)$ of respondents were VCT and $40.6 \%(n=171)$ of them were on WHO stage I of the disease when started ART treatment. Concerning to their health status, $62.0 \%(\mathrm{n}=$ $261)$ of the respondents were sick during diagnosed HIV positive. Similarly, about $67.6 \%(n=209)$ of them were on ART medication before disclosure of their HIV positive status to a sexual partner and about $49.4 \%$ ( $n=208$ ) of the respondents were to follow up care for $\geq 39$ months duration. When we came to the awareness of the sexual partner's HIV status, $68.4 \%(n=288)$ of them knew their sexual partner's HIV status; of them, $49.2 \%(n=207)$ had reported as having HIV positive partners [Table 3].

\section{The proportion of HIV positive status disclosure to the sexual partner}


About $73.4 \%(n=309)(95 \%, \mathrm{Cl}: 69-78)$ of the respondents disclosed their HIV positive status to the sexual partners. Out of these, $73.9 \%(n=311)$ of them had delayed their HIV positive status disclosure until after one month of the initial diagnosis. In addition, $39.2 \%(n=121)$ of the respondents had sex without a condom before disclosure of their HIV positive status to the sexual partners.

\section{Resigns to disclosure, HIV positive Status to sexual partner}

The most common reason to disclose HIV positive status to sexual partner was not to transmit the disease $34 \%(n=105)$, followed by to adhere to ART treatment $28.5 \%(n=88)$ [Figure 1].

\section{Barriers to disclosure, HIV positive status to sexual partner}

Likewise, the main barriers to disclose HIV positive status to sexual partner was fear of divorcing $56.3 \%$ $(n=63)$ followed by fear of breaking of confidentiality $25.9 \%(n=29)$ [Figure 2].

\section{Factors associated with HIV positive status disclosure to a sexual partner}

Variables such as sex, residence, occupation, living with sexual partners, having children, baseline WHO staging of the disease, health status during HIV testing, ART medication adherence, duration of ART follow up care, type of HIV testing, knowing sexual partner's HIV status, prior discussion about HIV testing, sees a person publicly disclosed his/her HIV status, Smoking cigarettes, chewing chat were candidates for multivariable analysis.

In the multiple logistic analysis male sex (AOR = 3.04; $95 \%, \mathrm{Cl}: 1.75-5.27)$, urban residence (AOR = 2.57; 95\%, Cl: 1.39-4.77), Good ART adherence status (AOR = 3.18; 95\%, Cl: 1.58-6.39), longer ART follow up care ( $\geq 39$ months) (AOR $=4.53 ; 95 \%, \mathrm{Cl}: 2.31-8.88)$, provider initiated HIV testing (AOR $=2.18 ; 95 \%, \mathrm{Cl}$ : 1.21-3.92), and knowing sexual partner's HIV status (AOR = 2.74; 95\%, Cl: 1.63-4.6)) Were statistical significantly associated with HIV positive status disclosure to sexual partner.

For further explanation, the odds of HIV positive status disclosure to sexual partner were 3 times more likely among males compared to females. Urban residents were nearly 2.6 times to disclose HIV positive status to sexual partners than rural residents. HIV positive status disclosure to sexual partner were 4.5 times higher among participants being on ART $\geq 39$ months when compared to these study participants being on ART <39 months duration. HIV positive status disclosure to sexual partner were 3.2 times more likely among study participant who adhere to ART medication compared to these study participants who did not adhere to ART medication.

Respondents who were tested by the initiation and counseling of health care provider were 2.2 times more likely to disclose HIV positive to sexual partner when compared to those participants whose HIV 
testing was VCT. Additionally, respondents who knew their partner's HIV status were 2.7 times more likely to disclose HIV positive to sexual partner when compared to these study participants who did not know their partner's HIV status [Table 3].

\section{Discussion}

Disclosure of HIV positive status to a sexual partner is among varies HIV prevention strategy to prevent the spread of infection. It is the base for accessing care and treatment programs, attains psycho-social support and reduces stigma, adheres to treatment and promotes safer health behavior particularly for couples.

In this study the magnitude of HIV positive status disclosure to sexual partner was $73.4 \%$ (95\%, Cl: 6978). This finding is lower than a study done in Zimbabwe 93\% (15). It is higher than the finding of studies conducted in China, $51 \%$ and in South-Western Uganda $75 \%(16,17)$. This discrepancy might be due to difference in population characteristic.

The finding of this study is lower than studies done in Ethiopia at Woldia Hospital ART clinic which was 76.6\%, in Hawassa University Referral Hospital ART clinic 85.7\% and at Kemissie Health center ART clinic $93.1 \%,(14,18,19)$. This discrepancy might be due to difference in methods used to assess HIV positive disclosure status where in the current study it was assessed from chart reviewed whereas in these studies, it was assessed through self-reporting questions.

The study found that male sex, urban residence, having children, knowing partner's HIV status, tested by health care provider initiated and counseling, Good ART adherence and longer ART follow up care were independent predictors of HIV positive status disclosure to sexual partner.

The odds of disclosing HIV positive status to sexual partner were three times more likely among male participants than female participants. This finding is similar to studies done in South Africa and in Tanzania $(20,21)$. This might be due to male partner dominancy which hindered females to disclose due to fear of partner's negative reaction.

Urban residents were 2.6 times more likely to disclose to sexual partner than rural residents. This finding is supported by study done at in South-Western Uganda (17). The possible justification for this is urban dwellers might get adequate HIV related information than rural residents.

The odds of disclosing HIV positive status to sexual partner among study participants who were on ART follow up care for $\geq 39$ month's duration were 4.5 times more likely than study participants being on ART for $<39$ months duration. This finding is supported by a study done at Michelle Referral Hospital in Ethiopia (13), in France and in Nigeria $(22,23)$. The possible explanation for this might be the result of a continuous counseling at each contact with health professionals and helping patients to develop healthy behaviors including disclosure to sexual partner. 
When we goes to ART medication adherence, HIV positive status disclosure to sexual partner was 3.2 times more likely among respondents who had good ART medication adherence than poor ART medication adherence status. This finding is similar to a study done in Togo (24). This might be respondents may receive information continually and encouragement for caregivers to create favorable psychological conditions to disclose their HIV sero-positive status to their sexual partners.

In another way, HIV positive status disclosure to sexual partner were 2.2 times more likely among study participants whose HIV testing type was provider initiated than client initiated testing. This is similar with a study done at Woldia hospital ART clinic in Ethiopia (18). This might be due to getting more information regarding to the benefit of disclosure to a sexual partner.

Lastly but not least, Knowing partner HIV status was positively associated with status disclosure. Respondents who knew their sexual partner's HIV status were about 2.7 times more likely to disclose their HIV status to their partner as compared to those who did not know their partner's HIV status. This is also in line with other studies conducted in Bale Zone Hospital, Woldia hospital, Kemissie health center in Ethiopia $(12,14,18)$ and in Ogun State in Nigeria and in Togo regional hospital $(24,25)$. Because of aware of sexual partner's HIV positive status may encourage partners to disclosure for the purpose of preventing HIV transmission and to support each other.

\section{Limitation Of The Study}

The reported nature of the data collection approach could be affected by social desirability bias which is an important issue with regards to the sensitive topic such as HIV positive status disclosure

\section{Conclusion And Recommendation Conclusion}

In this study, HIV positive status disclosure to sexual partners was low. The study also found significant association between male sex, urban resident, Knowing the partners HIV status, longer ART follow up care ( $\geq 39$ months), Good ART adherence status, and heath care provider initiated HIV testing with HIV positive status disclosure to a sexual partner.

\section{Recommendation}

\section{For Health care providers}

It is better to promote ongoing ART adherence counseling services and provider initiated HIV testingthrough extensive health education particularly, for females and rural residents. Furthermore, health education programs should be focused on promoting mutual partner HIV testing to increase the awareness of partner's HIV status. 
For Government and None Governmental Organization

It is better to focus on promoting HIV disclosure status for planning of future interventions among women and rural residents and to encourage provider initiated HIV testing widely

For Researchers

This study did not address health service provider and related factors. Therefore, it is better to carry out further study to address these variables.

\section{Abbreviations}

AIDS: Acquired Immune Deficiency Syndrome; ART: Antiretroviral Treatment; DMHC: Debre Markos Health Center; DMRH: Debre Markos Referral Hospital; EDHS: Ethiopian Demographic and Health Survey; HAART: Highly Active Antiretroviral Treatment; HDH: Hidase Health Center; HIV: Human Immune Virus; PITC: provider initiated HIV testing and counseling; PLWAHIV: People Living with HIV AIDS; PMTCT: Prevention of Mother to Child Transmission; UNAIDS: Joint United Nations Program on HIV/ADIS; VCT: Voluntary Counseling and Testing; WHC: Wuseta Health Center

\section{Declarations}

\section{Ethics approval and consent to participate}

First, the ethical clearance letter was obtained from the Ethical Review Committee of the Debre Markos University, college of health science. Permission letter was obtained from each health facility administrative body and given to the respective ART unit. The Data collection was made after written consent was taken from each participant. The privacy and confidentiality of the respondents were ensured by excluding the name on the questionnaire and interviewed them in a private space that is free from interruption and cannot be observed or heard by other people within the facility environment.

\section{Consent to publication}

Not applicable.

\section{Availability of data and materials}

The data can be accessed from the corresponding author through the following address mengistubinayew7@gmail.com. The data might be accessed if and only if for research purpose.

\section{Competing interests}


The authors declare that they have no competing interests.

\section{Funding}

Not applicable

\section{Authors' contributions}

MB was participated in the title selection, design, and statistical analysis, and interpretation of results. MT and $\mathrm{HZ}$ were involved in this thesis research by giving suggestions, comments, supports, encourages, and contribution from the beginning of the research proposal throughout the thesis work. AF was involved in manuscript drafting, critical interpretation, and critical revision in addition to he was participating during in tittle selection. All authors read and have given approval for this manuscript to be published.

\section{Acknowledgments}

First of all, we would like to thank Debre Markos University for giving me the chance to develop this research work.

Second, we would like to thank all the data collectors for their faithfulness to collect the data.

Third, our acknowledgement goes to all study participants and all facilities or ART clinics that provided the necessary information for this study.

Lastly, we would like to acknowledge everybody that we have not mentioned above, your technical support and contribution was a blessing and God will bless you abundantly.

\section{Authors Information}

- Debre Markos University, Debre Markos, East Gojam Zone, Amhara Regional State, Ethiopia

- College of medicine and health science, Debre Markos University, Debre Markos, East Gojam zone, Amhara regional state, Ethiopia.

- College of medicine and health science, Debre Markos University, Debre Markos, East Gojam zone, Amhara regional state, Ethiopia.

- Department of public health, College of health science, Salale university, Fitche, North Shewa Zone, Ethiopia

\section{References}


1.Obermeyer CM, Baijal P, Pegurri E. Facilitating HIV disclosure across diverse settings: a review. American journal of public health. 2011;101(6):1011-23.

2.World Health Organization. Global HIV/ADIS Fact Sheet/UNADIS Zuzerland, Geneva. Available from: http://www.unaids.org/en/resources/fact-sheet. 2017.

3.World Health Organization. Gender Dimensions of HIV status Discourse to Sexual partners. Rates, Barriers \& outcomes: A Review paper. WHO. Geneva, Switzerland. 2004.

4.WHO Guidelines on HIV self-testing and partner notification. Global analysis of policies on partner notification. 2016.

5.UNAIDS/WHO: Opening up the HIV/AIDS Epidemic: Guid-ance on encouraging beneficial disclosure, ethical partnercounseling \& appropriate use of HIV case reporting.UNAIDS/00.42E, Geneva. 2000.

6.CDC: Revised guidelines for HIV counseling, testing andreferral.MMWR Morbidity and Mortality Weekly Report 2002. p. 1-57.

7.McGrath CJ, Singa B LA, Kinuthia J RK, Omolo D OB, Wafula R, Muange P ea. Non-disclosure to male partners and incomplete PMTCT regimens associated with higher risk of mother-to-child HIV transmission: a national survey in Kenya. AIDS care. 2018;30(6):765-73.

8.Sendo EG, Cherie A, Erku TA. Disclosure experience to partner and its effect on intention to utilize prevention of mother to child transmission service among HIV positive pregnant women attending antenatal care in Addis Ababa, Ethiopia. BMC Public Health. 2013;13:765.

9.Fituma S, DT N,. HIV Positive Status Disclosure And Highly Active Antiretroviral Therapy Adherence Among People Living With HIV In Ambo Hospital, West Shewa Zone, Oromia Region, Ethiopia. Obstet Gynecol Int J 2016;5(2).

10.Evangeli M, Wroe AL. HIV Disclosure Anxiety: A Systematic Review and Theoretical Synthesis. AIDS Behav. 2017;21(1):1-11.

11.Ssali SN, Atuyambe L, Tumwine C, Segujja E, Nekesa N, Nannungi A, et al. Reasons for disclosure of HIV status by people living with HIV/AIDS and in HIV care in Uganda: an exploratory study. AIDS Patient Care STDS. 2010;24(10):675-81.

12.Geremew TD, Nuri RA, Esmael JK. Sero Status Disclosure to Sexual Partner and Associated Factors among Adult HIV Positive Patients in Bale Zone Hospitals, Oromia Region, Ethiopia: Institution Based Cross-Sectional Study. Open Journal of Epidemiology. 2018;8(02):43.

13.Gultie T, Genet M, Sebsibie G. Disclosure of HIV-positive status to sexual partner and associated factors among ART users in Mekelle Hospital. Hiv/Aids. 2015;7:209-14. 
14.Seid M, Wasie B, Admassu M. Disclosure of HIV positive result to a sexual partner among adult clinical service users in Kemissie District, northeast Ethiopia African Journal of Reproductive Health. 2012;16(1):97-105.

15.Shamu S, Zarowsky C, Shefer T, Temmerman M, N. A. Intimate partner violence after disclosure of HIV test results among pregnant women in Harare, Zimbabwe. PLoS. 2014;9(10,e109447.).

16.Shan Qiao, Xiaoming Li, Yuejiao Zhou, Shen Z, Zhenzhu. interpersonal factors associated with HIV partner disclosure among HIV-infected people in China. AIDS Care,. 2015:37-43,.

17.Ngonzi J, Godfrey M, Kivunike M, Julius M,. SW. Predictors and Patterns of HIV Status Disclosure among HIV Positive Pregnant Women at Mbarara Regional Referral Hospital, South-Western Uganda. Obstet Gynecol Int J. 2017;6(6).

18.Erku TA, Megabiaw B, Wubshet M. Predictors of HIV status disclosure to sexual partners among people living with HIV/AIDS in Ethiopia. The Pan African Medical Journal. 2012;13.

19.Gari T, Habte D, Markos E. HIV positive status disclosure among women attending art clinic at Hawassa University Referral Hospital, South Ethiopia. East African Journal of Public Health. 2010;7(1).

20.Longinetti E, Santacatterina M, El-Khatib Z. Gender perspective of risk factors associated with disclosure of HIV status, a cross-sectional study in Soweto, South Africa. PloS one. 2014;9(4):e95440.

21.Kiula ES, Damian DJ, Msuya SE. Predictors of HIV serostatus disclosure to partners among HIVpositive pregnant women in Morogoro, Tanzania. BMC Public Health. 2013;13:433.

22.Kankou JM, Bouchaud O, Lele N, Bourgeois D, Spire B, Carrieri MP, et al. Factors Associated with HIV Status Disclosure in HIV-Infected Sub-Saharan Migrants Living in France and Successfully Treated with Antiretroviral Therapy: Results from the ANRS-VIHVO Study. J Immigr Minor Health. 2017;19(4):843-50.

23.Oseni OE, Okafor IP, Sekoni AO. Issues Surrounding HIV Status Disclosure: Experiences of Seropositive Women in Lagos, Nigeria. International journal of preventive medicine. 2017;8:60.

24.Yaya I, Saka B, Landoh DE, Patchali PM, Patassi AA, Aboubakari AS, et al. HIV status disclosure to sexual partners, among people living with HIV and AIDS on antiretroviral therapy at Sokode regional hospital, Togo. PloS one. 2015;10(2):e0118157.

25.Amoran OE. Predictors of disclosure of sero-status to sexual partners among people living with HIV/AIDS in Ogun State, Nigeria. Nigerian journal of clinical practice. 2012;15(4):385-90.

\section{Tables}

Table 1: Sample size determination for the second objective (factors associated HIV status disclosure) among adult HIV positive clients on follow up care at public ART clinic in Debre Markos town, 
in $2019(\mathrm{~N}=421)$

\begin{tabular}{|c|c|c|c|c|}
\hline Author & Variables significantly associated & \multicolumn{2}{|c|}{ HIV disclosure to a sexual partner } & $\begin{array}{c}\text { Sample } \\
\text { Size }\end{array}$ \\
\hline \multirow{6}{*}{ (12) } & \multirow[t]{2}{*}{ Urban residence } & $\%$ in exposed group & $P 1=58.01 \%$ & \\
\hline & & $\begin{array}{l}\% \text { in non-exposed } \\
\text { group }\end{array}$ & $\mathrm{P} 2=42.95 \%$ & 370 \\
\hline & \multirow{2}{*}{$\begin{array}{l}\text { Receiving disclosure counseling } \\
\text { service }\end{array}$} & $\%$ in exposed group & $P 1=91.66 \%$ & \\
\hline & & $\begin{array}{l}\% \text { in non-exposed } \\
\text { group }\end{array}$ & $P 2=58.97 \%$ & 64 \\
\hline & \multirow{2}{*}{$\begin{array}{l}\text { Knowledge of sexual partner's HIV } \\
\text { status }\end{array}$} & $\%$ in exposed group & $\mathrm{P} 1=64.05 \%$ & \\
\hline & & $\begin{array}{l}\text { \% in non-exposed } \\
\text { group }\end{array}$ & $P 2=27.69 \%$ & 66 \\
\hline
\end{tabular}

Then by adding $10 \%$ non-response rate for $n=370$, it becomes, $\mathbf{n} \mathbf{=} \mathbf{4 0 7}$. Since the sample size is larger for the first objective, we take the final sample size to be $\mathbf{=} \mathbf{4 2 1}$.

Table 2: Socio-demographic characteristics of adult HIV positive clients on follow up care at public ART clinic in Debre Markos town, in $2019(\mathrm{~N}=421)$ 


\begin{tabular}{|c|c|c|c|c|}
\hline Variables & Category & Frequency & Percentage & $x^{2}, p$ \\
\hline \multirow[t]{4}{*}{ Age } & $18-27$ & 70 & 16.6 & \multirow{4}{*}{$\begin{array}{l}X^{2}=4.108 \\
P=0.250\end{array}$} \\
\hline & $28-37$ & 182 & 43.2 & \\
\hline & $38-47$ & 100 & 23.8 & \\
\hline & $\geq 48$ & 69 & 16.4 & \\
\hline \multirow[t]{2}{*}{ Sex } & Male & 200 & 47.5 & \multirow[b]{2}{*}{$\begin{array}{l}X^{2}=5.082 \\
P=0.024\end{array}$} \\
\hline & Female & 221 & 52.5 & \\
\hline \multirow[t]{2}{*}{ Residence } & Urban & 337 & 80.0 & \multirow[b]{2}{*}{$\begin{array}{l}X^{2}=4.461 \\
P=0.035\end{array}$} \\
\hline & Rural & 84 & 20.0 & \\
\hline \multirow[t]{2}{*}{ Religion } & Orthodox & 411 & 97.6 & \multirow{2}{*}{$\begin{array}{l}X^{2}=1.446 \\
P=0.229\end{array}$} \\
\hline & Others & 10 & 2.4 & \\
\hline \multirow[t]{2}{*}{ Ethnicity } & Amhara & 414 & 98.3 & \multirow{2}{*}{$\begin{array}{l}X^{2}=0.141 \\
P=0.707\end{array}$} \\
\hline & Others & 7 & 1.7 & \\
\hline \multirow[t]{4}{*}{ Marital status } & Single & 42 & 10 & \multirow{4}{*}{$\begin{array}{l}X^{2}=2.006, P= \\
0.571\end{array}$} \\
\hline & Married & 264 & 62.7 & \\
\hline & Divorced & 80 & 19 & \\
\hline & Widowed & 35 & 8.3 & \\
\hline \multirow[t]{4}{*}{ Educational status } & $\begin{array}{l}\text { Unable to read and } \\
\text { write }\end{array}$ & 132 & 31.3 & \multirow{4}{*}{$\begin{array}{l}X^{2}=2.627, \\
P=0.453\end{array}$} \\
\hline & Able to read and write & 55 & 13.1 & \\
\hline & Primary school & 99 & 23.5 & \\
\hline & Secondary and above & 135 & 32.1 & \\
\hline \multirow[t]{2}{*}{ Occupations } & Employed & 120 & 28.5 & \multirow{2}{*}{$\begin{array}{l}X^{2}=2.989 \\
P=0.084\end{array}$} \\
\hline & Unemployed & 301 & 71.5 & \\
\hline \multirow[t]{2}{*}{ Has children } & Yes & 273 & 64.8 & \multirow{2}{*}{$\begin{array}{l}X^{2}=11.417 \\
P=0.001\end{array}$} \\
\hline & No & 148 & 35.2 & \\
\hline \multirow[t]{2}{*}{ Number of children } & 1. Children & 211 & 77.3 & \multirow[t]{2}{*}{$\begin{array}{l}X^{2}=0.833 \\
P=0.361\end{array}$} \\
\hline & $>2$ children & 62 & 22.7 & \\
\hline
\end{tabular}




\begin{tabular}{ccc} 
Yes & 301 & 71.5 \\
\hline No & 120 & 28.5 \\
\hline
\end{tabular}

$X^{2}=6.786$, $P=0.009$

Table 3: Clinical condition, partner and social related factors of adult HIV positive clients on follow up care at ART clinic, in Debre Markos town public, in $2019(\mathrm{~N}=421)$ 


\begin{tabular}{|c|c|c|c|c|}
\hline Variables & Category & Frequency & Percentage & $x^{2}, p$ \\
\hline \multirow[t]{2}{*}{ Health status in HIV diagnosis } & Well & 160 & 38.0 & \multirow[t]{2}{*}{$X^{2}=4.596, P=0.032$} \\
\hline & Sick & 261 & 62.0 & \\
\hline \multirow{4}{*}{$\begin{array}{l}\text { Baseline WHO stage of the } \\
\text { disease }\end{array}$} & Stage I & 171 & 40.6 & \multirow[t]{4}{*}{$X^{2}=57.031, P<0.001$} \\
\hline & Stage II & 107 & 25.4 & \\
\hline & Stage III & 122 & 29.0 & \\
\hline & Stage IV & 21 & 5.0 & \\
\hline \multirow[t]{2}{*}{ HIV testing type } & Client initiated & 256 & 60.8 & \multirow[t]{2}{*}{$X^{2}=20.205, P<0.001$} \\
\hline & $\begin{array}{l}\text { Provider } \\
\text { initiated }\end{array}$ & 165 & 39.2 & \\
\hline \multirow{3}{*}{$\begin{array}{l}\text { Number of lifetime sexual } \\
\text { partners }\end{array}$} & One & 123 & 29.2 & \multirow[t]{3}{*}{$X^{2}=0.921, P=0.631$} \\
\hline & $2-3$ & 248 & 58.9 & \\
\hline & $\geq 4$ & 50 & 11.9 & \\
\hline \multirow{2}{*}{$\begin{array}{l}\text { Number of sexual partners } \\
\text { while HIV diagnosis }\end{array}$} & One & 400 & 95.1 & \multirow[t]{2}{*}{$X^{2}=0.044, P=0.834$} \\
\hline & $\geq 2$ & 21 & 4.9 & \\
\hline \multirow[t]{2}{*}{ Knowing the partner HIV status } & Yes & 288 & 68.4 & \multirow{2}{*}{$\begin{array}{l}X^{2}=27.239 \\
P<0.001\end{array}$} \\
\hline & No & 133 & 31.6 & \\
\hline \multirow[t]{3}{*}{ Sexual partner`s HIV status } & HIV positive & 207 & 49.2 & \multirow{3}{*}{$X^{2}=0.074, P=0.785$} \\
\hline & HIV negative & 81 & 19.2 & \\
\hline & Not known & 133 & 31.6 & \\
\hline \multirow{2}{*}{$\begin{array}{l}\text { Relationship status before } \\
\text { testing }\end{array}$} & Smooth & 312 & 74.1 & \multirow[t]{2}{*}{$X^{2}=0.254, P=0.614$} \\
\hline & Disagreement & 109 & 25.9 & \\
\hline \multirow[t]{3}{*}{ Relationship dominancy } & Himself & 379 & 90 & \multirow[t]{3}{*}{$X^{2}=0.013, P=0.993$} \\
\hline & Herself & 23 & 5.5 & \\
\hline & $\begin{array}{l}\text { No } \\
\text { domination }\end{array}$ & 19 & 4.5 & \\
\hline \multirow{2}{*}{$\begin{array}{l}\text { ART medication adherence } \\
\text { status }\end{array}$} & Good & 374 & 88.8 & \multirow{2}{*}{$\begin{array}{l}X^{2}=16.212 \\
P<0.001\end{array}$} \\
\hline & Poor & 47 & 11.2 & \\
\hline \multirow{2}{*}{$\begin{array}{l}\text { Duration of ART followup care } \\
\text { in months }\end{array}$} & $1-12$ & 105 & 24.94 & \multirow{2}{*}{$\begin{array}{l}X^{2}=33.054 \\
P<0.001\end{array}$} \\
\hline & $13-25$ & 91 & 21.62 & \\
\hline
\end{tabular}




\begin{tabular}{|c|c|c|c|c|}
\hline & $26-38$ & 35 & 8.31 & \\
\hline & $\geq 39$ & 190 & 45.13 & \\
\hline \multirow{2}{*}{$\begin{array}{l}\text { Prior discussion about HIV } \\
\text { testing }\end{array}$} & Yes & 99 & 23.5 & \multirow[t]{2}{*}{$X^{2}=1.470, P=0.225$} \\
\hline & No & 322 & 76.5 & \\
\hline \multirow{2}{*}{$\begin{array}{l}\text { See a person publically } \\
\text { disclosed HIV status }\end{array}$} & Yes & 112 & 26.6 & \multirow[t]{2}{*}{$X^{2}=5.278, P=0.022$} \\
\hline & No & 309 & 73.4 & \\
\hline \multirow{2}{*}{$\begin{array}{l}\text { Being a member of HIV/ADIS } \\
\text { club }\end{array}$} & Yes & 98 & 23.3 & \multirow[t]{2}{*}{$X^{2}=1.129, P=0.288$} \\
\hline & No & 323 & 76.7 & \\
\hline \multirow{2}{*}{$\begin{array}{l}\text { Drink alcohol during HIV } \\
\text { diagnosis }\end{array}$} & Yes & 106 & 25.2 & \multirow[t]{2}{*}{$X^{2}=0.312, P=0.576$} \\
\hline & No & 315 & 74.8 & \\
\hline \multirow[t]{2}{*}{ Chew chat during HIV diagnosis } & Yes & 15 & 3.6 & \multirow[t]{2}{*}{$X^{2}=1.430, P=0.232$} \\
\hline & No & 406 & 96.4 & \\
\hline \multirow{2}{*}{$\begin{array}{l}\text { Smoke cigarette during HIV } \\
\text { diagnosis }\end{array}$} & Yes & 16 & 3.8 & \multirow[t]{2}{*}{$X^{2}=2.504, P=0.114$} \\
\hline & No & 405 & 96.2 & \\
\hline
\end{tabular}

Table 4: Bivariate and Multivariate analysis of factors associated with HIV status disclosure to sexual partner among adult HIV positive clients on ART follow up care at a public ART clinic in Debre Markos town, 2019. 


\begin{tabular}{|c|c|c|c|c|c|c|}
\hline \multirow[t]{2}{*}{ Variables } & & \multicolumn{2}{|c|}{$\begin{array}{l}\text { HIV status } \\
\text { disclosure }\end{array}$} & \multirow[t]{2}{*}{ COR (95\% Cl) } & \multirow[t]{2}{*}{ AOR $(95 \% \mathrm{Cl})$} & \multirow[t]{2}{*}{ P-value } \\
\hline & & Yes & No & & & \\
\hline \multirow[t]{2}{*}{ Sex } & Male & 157 & 43 & $1.66(1.07-2.58)$ & $\begin{array}{l}3.04(1.75- \\
5.27)\end{array}$ & ¿. 001 * \\
\hline & Female & 152 & 69 & 1.00 & 1.00 & \\
\hline \multirow[t]{2}{*}{ Residence } & Urban & 255 & 82 & $1.73(1.04-2.88)$ & $\begin{array}{l}2.57(1.39- \\
4.77)\end{array}$ & $0.003^{*}$ \\
\hline & Rural & 54 & 30 & 1.00 & 1.00 & \\
\hline \multirow[t]{2}{*}{ Occupation } & Employed & 81 & 39 & 1.00 & 1.00 & \\
\hline & Unemployed & 228 & 73 & $1.50(0.95-2.39)$ & $\begin{array}{l}1.65(0.95- \\
2.87)\end{array}$ & 0.075 \\
\hline \multirow[t]{2}{*}{$\begin{array}{l}\text { Living with sexual } \\
\text { partner }\end{array}$} & Yes & 231 & 70 & $1.78(1.12-2.82)$ & $\begin{array}{l}1.23(0.67- \\
2.25)\end{array}$ & 0.506 \\
\hline & No & 78 & 42 & 1.00 & 1.00 & \\
\hline \multirow{2}{*}{$\begin{array}{l}\text { Baseline WHO } \\
\text { staging }\end{array}$} & Stage I-II & 243 & 98 & 1.00 & 1.00 & \\
\hline & Stage III-IV & 66 & 14 & $1.90(1.02-3.54)$ & $\begin{array}{l}1.96(0.94- \\
4.06)\end{array}$ & 0.072 \\
\hline \multirow{4}{*}{$\begin{array}{l}\text { ART duration in } \\
\text { months }\end{array}$} & $1-12$ & 63 & 42 & 1.00 & 1.00 & \\
\hline & $13-25$ & 57 & 34 & $1.12(0.63-1.99)$ & $\begin{array}{l}1.25(0.65- \\
2.42)\end{array}$ & 0.509 \\
\hline & $26-38$ & 24 & 11 & $1.46(0.65-3.28)$ & $\begin{array}{l}1.05(0.41- \\
2.67)\end{array}$ & 0.925 \\
\hline & $\geq 39$ & 165 & 25 & $4.4(2.48-7.81)$ & $\begin{array}{l}4.53(2.31- \\
8.88)\end{array}$ & <. $001 *$ \\
\hline \multirow{2}{*}{$\begin{array}{l}\text { Health status } \\
\text { during testing }\end{array}$} & Healthy & 108 & 52 & 1.00 & & \\
\hline & Sick & 201 & 60 & $1.61(1.04-2.50)$ & $\begin{array}{l}1.49(0.88- \\
2.50)\end{array}$ & 0.136 \\
\hline \multirow{2}{*}{$\begin{array}{l}\text { ART } \\
\text { Adherence status }\end{array}$} & Good & 286 & 88 & $3.39(1.83-6.30)$ & $\begin{array}{l}3.18(1.58- \\
6.39)\end{array}$ & $0.001 *$ \\
\hline & Poor & 23 & 24 & 1.00 & 1.00 & \\
\hline \multirow[t]{2}{*}{ HIV Test type } & $\begin{array}{l}\text { Provider } \\
\text { initiated }\end{array}$ & 141 & 24 & $3.08(1.86-5.09)$ & $\begin{array}{l}2.18(1.21- \\
3.92)\end{array}$ & $0.009 *$ \\
\hline & Client & 168 & 88 & 1.00 & 1.00 & \\
\hline
\end{tabular}


initiated

\begin{tabular}{|c|c|c|c|c|c|c|}
\hline \multirow{2}{*}{$\begin{array}{l}\text { Knowing sexual } \\
\text { partner's HIV } \\
\text { status }\end{array}$} & Yes & 232 & 54 & $3.24(2.06-5.08)$ & $\begin{array}{l}2.74(1.63- \\
4.63)\end{array}$ & 0.001* \\
\hline & No & 77 & 58 & 1.00 & 1.00 & \\
\hline \multirow[t]{2}{*}{$\begin{array}{l}\text { Prior discussion } \\
\text { about HIV testing }\end{array}$} & Yes & 68 & 31 & $0.73(0.45-1.21)$ & $\begin{array}{l}0.92(0.48- \\
1.79)\end{array}$ & 0.085 \\
\hline & No & 241 & 81 & 1.00 & & \\
\hline \multirow[t]{2}{*}{$\begin{array}{l}\text { See public } \\
\text { disclosure }\end{array}$} & Yes & 73 & 39 & $0.58(0.36-0.93)$ & $\begin{array}{l}0.36(0.36- \\
1.12)\end{array}$ & 0.108 \\
\hline & No & 236 & 73 & 1.00 & & \\
\hline \multirow[t]{2}{*}{ Chewing chat } & Yes & 9 & 6 & $0.53(0.18-1.52)$ & $0.39(0.10,1.50)$ & 0.172 \\
\hline & No & 300 & 106 & 1.00 & & \\
\hline \multirow[t]{2}{*}{ Smoking cigarette } & Yes & 9 & 7 & $0.45(016-1.24)$ & $\begin{array}{l}1.09(0.25- \\
4.78)\end{array}$ & 0.911 \\
\hline & No & 300 & 105 & 1.00 & & \\
\hline
\end{tabular}

NB: * stands for variables that showed significant association in the multivariate analysis.

\section{Figures}

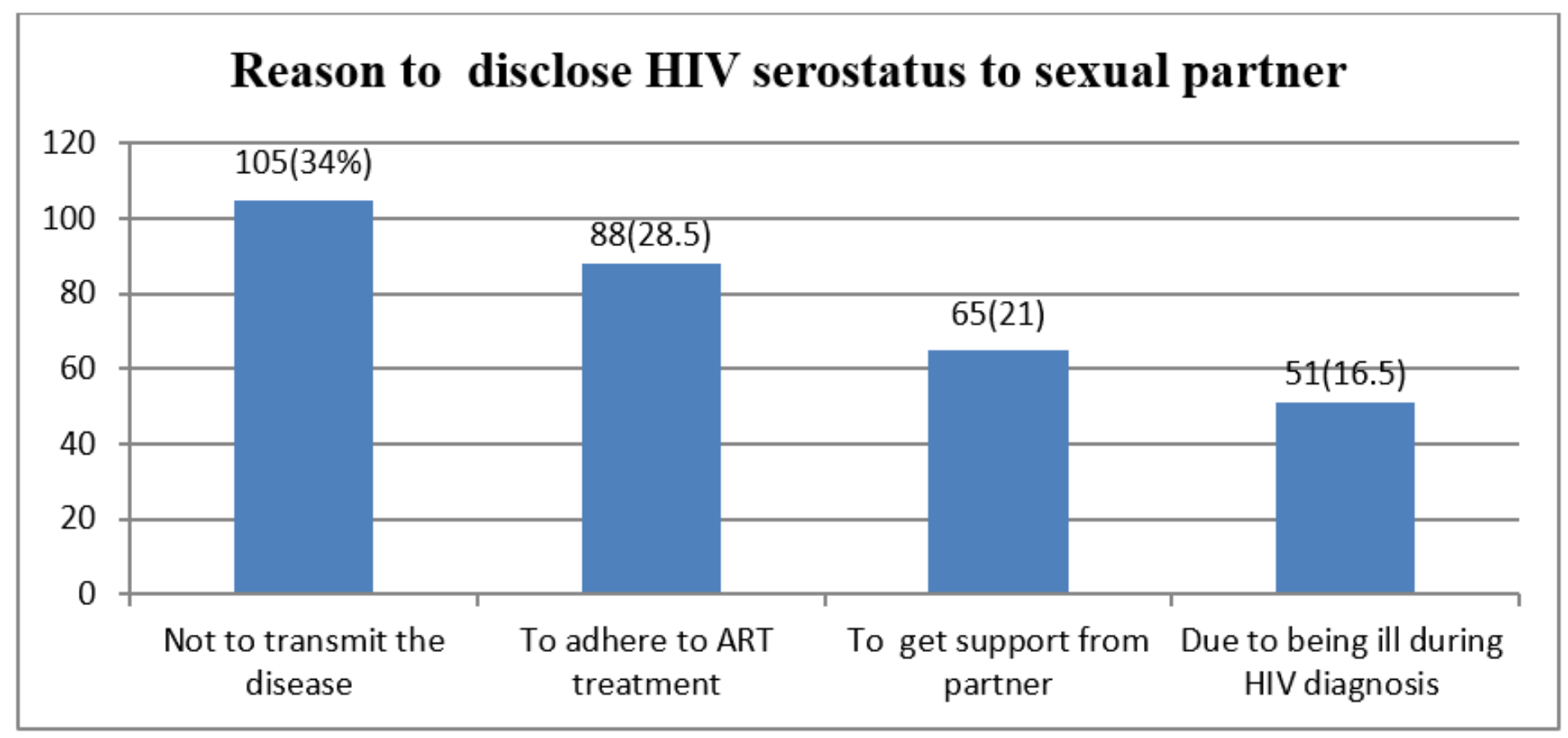

Figure 1 
Reasons to disclose HIV status to sexual partners among adult HIV positive clients on follow up care at a public ART clinic in Debre Markos town, 2019.

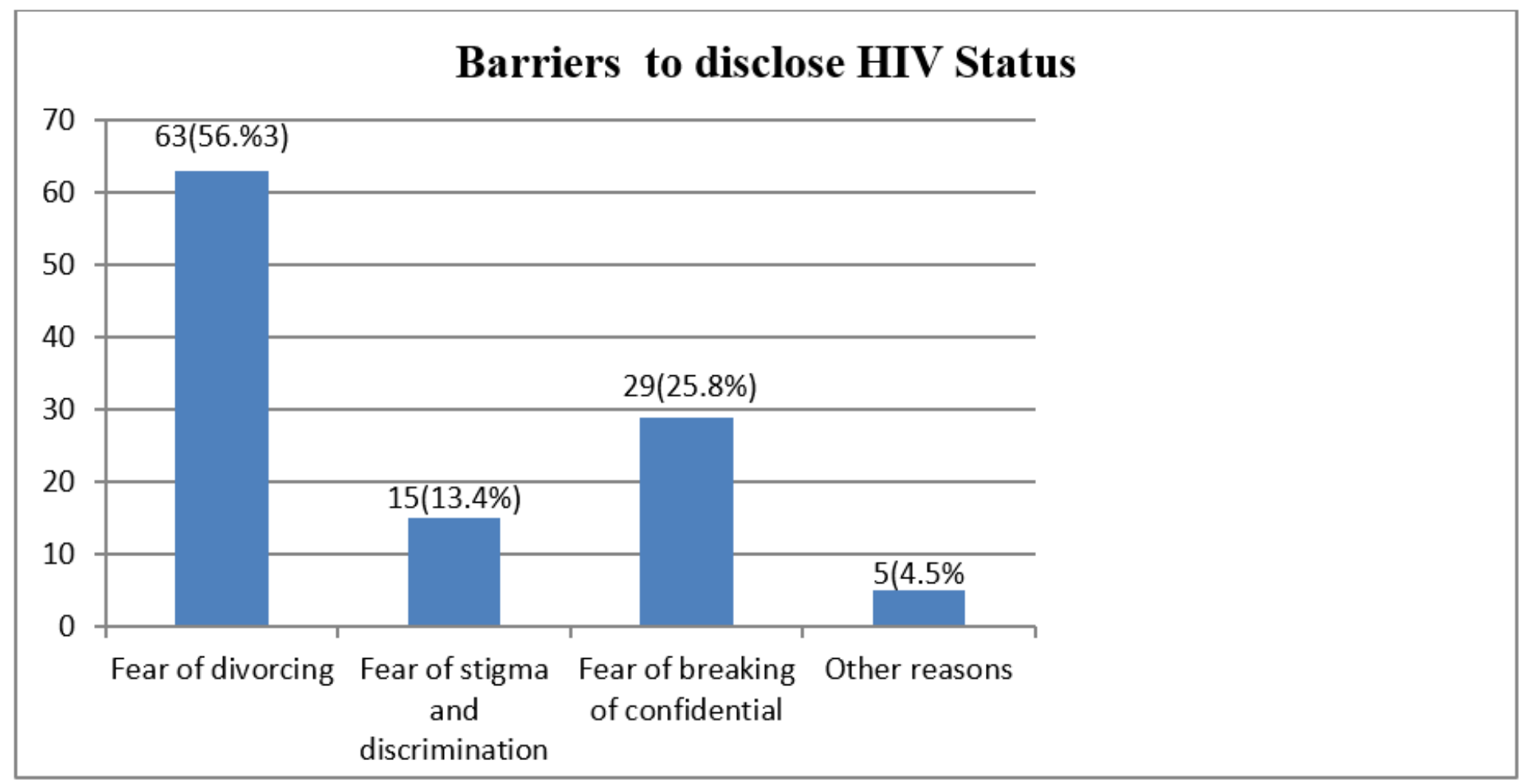

\section{Figure 2}

Reasons not to disclose HIV positive status to a sexual partner by adult HIV positive clients on follow up care in Debre Markos Town public ART clinic, 2019. 